\title{
Campus Teaching Awards Academic Year 2017-18
}

PSA is pleased to recognize the recipients of campus-wide and departmental awards for teaching excellence during the 2017-18 academic year. Their contributions to teaching, mentorship, and future students create a lasting legacy in political science.

(Photos appear above recipient's name and institution.)

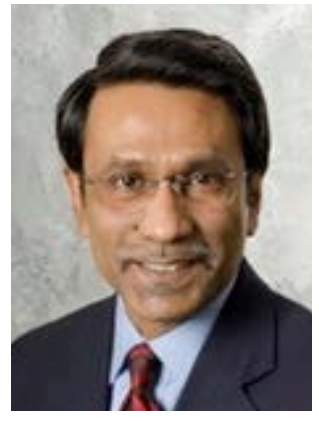

Ali Riaz, Illinois State University Office of the Provost's Distinguished Professor Award

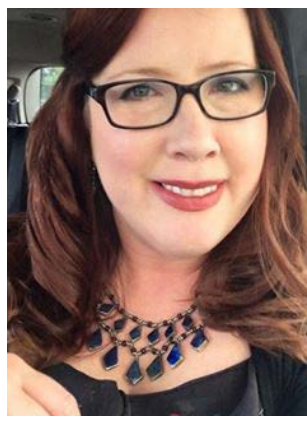

Leda Barnett, Our Lady of the Lake University

The Francine Fleming Endowed Award for Teaching Excellence 2017

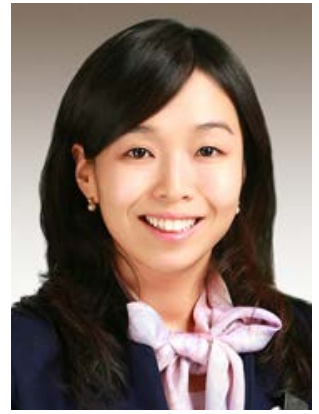

Ñusta Carranza Ko, Ohio Northern University

Getty College of Arts and Sciences Teaching Award

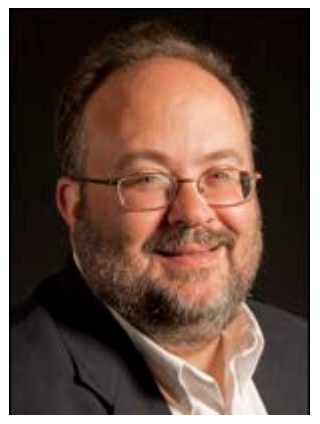

Victor Asal, University at Albany, SUNY 2018 Torch Award

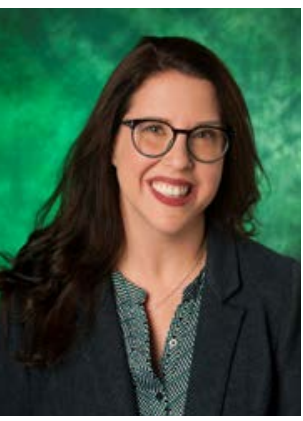

Bethany Blackstone, University of North Texas

University of North Texas President's Council Teaching Award

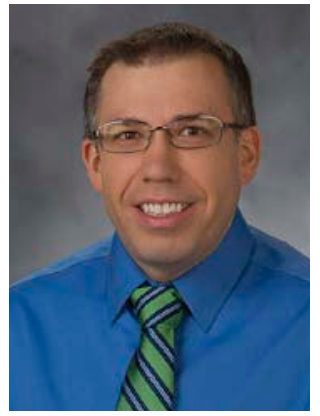

Brian DiSarro, Sacramento State University

Sacramento State University Faculty Senate's Outstanding Teaching Award

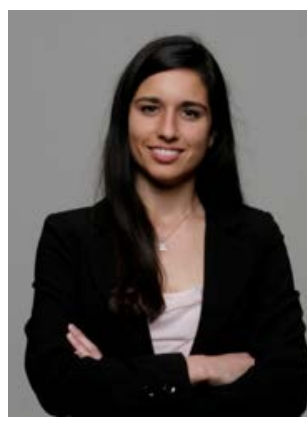

Christina Noriega Bambrick, University of Texas at Austin

2018 University of Texas Liberal Arts Council's Excellence in Teaching Award

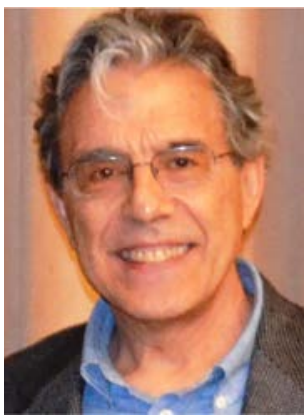

Carlos Parodi, Illinois State University Office of International Studies and Programs Faculty/Staff Internationalization Award

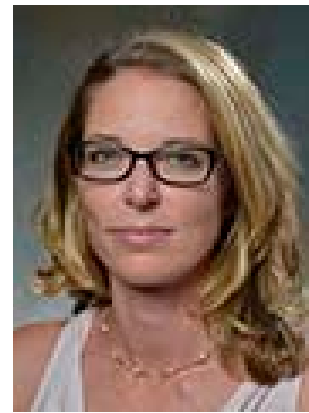

Kathleen Donovan, St. John Fisher College

Award for Teaching Excellence 


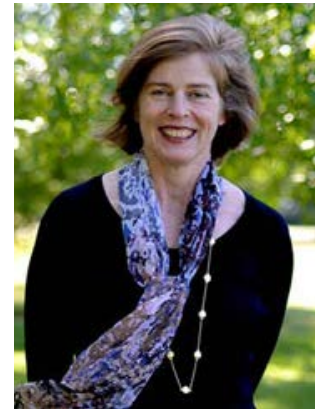

Barbara Donovan, Wesleyan College Student Government Association Professor of the Year

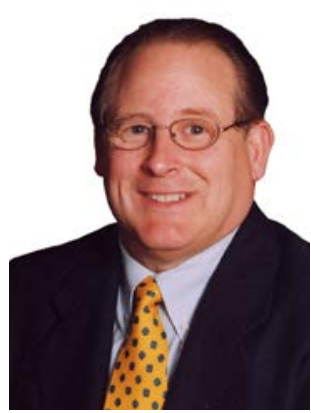

Richard Farkas, DePaul University Thomas and Carol Dammrich Faculty Innovation Award

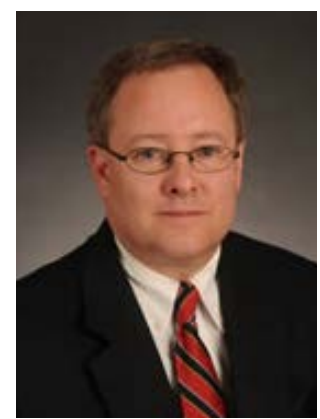

Michael Hail, Morehead State University Student Government Association's Educational Excellence Award

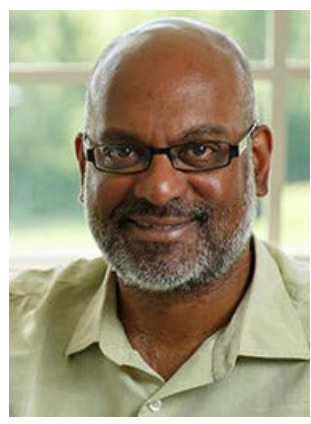

Michael James, Bucknell University Class of 1956 Lectureship Award for Inspirational Teaching

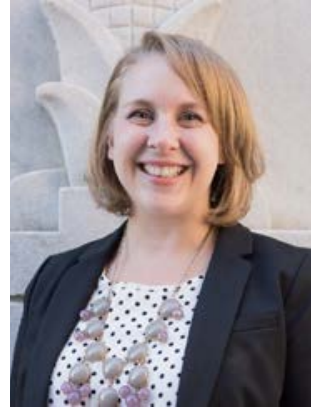

Lauren Elliott-Dorans, Ohio University Dean's Outstanding Teaching Award

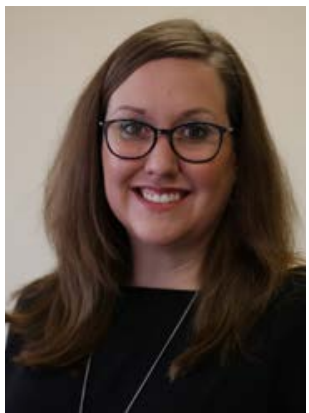

Rebecca Flavin, Baylor University Carr P. Collins Outstanding Professor Award

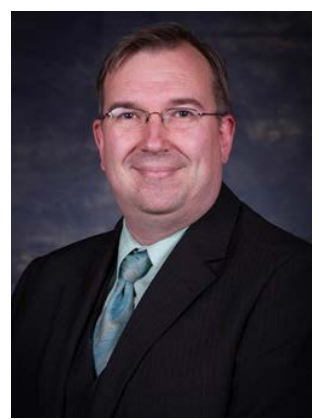

Leif Hoffmann, Lewis-Clark State College

Dr. Cameron \& Marilyn Hinman Employee Excellence Award

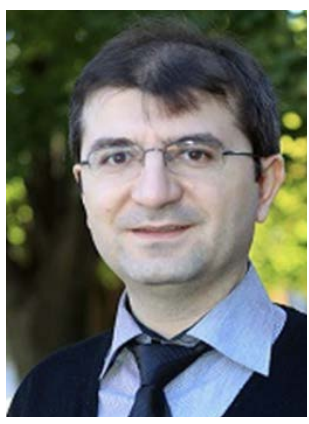

Ramazan Kilinc, University of Nebraska at Omaha

2018 Alumni Outstanding Teaching Award

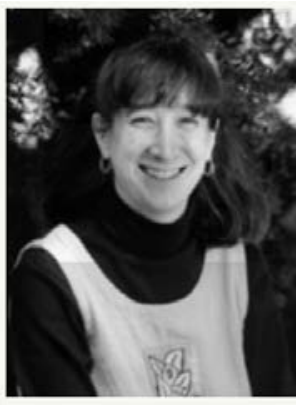

Judith Lynn Failer, Indiana University Trustees Teaching Award

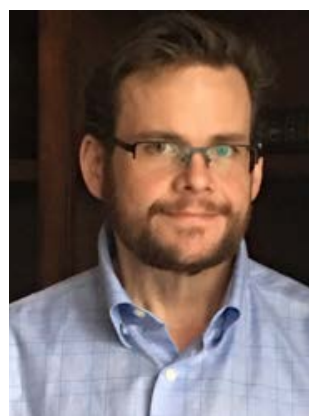

Michael Greig, University of North Texas J.H. Shelton Excellence in Teaching Award

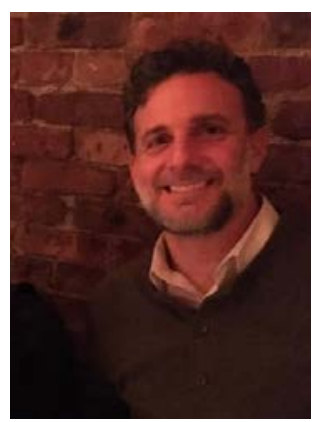

Richard Holtzman, Bryant University Bryant University Recognition for Meritorious Teaching

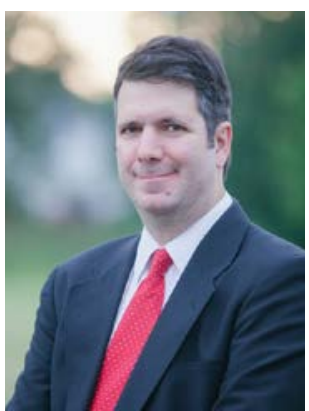

L.J. Zigerell, Illinois State University 2018 University Research Initiative Award 


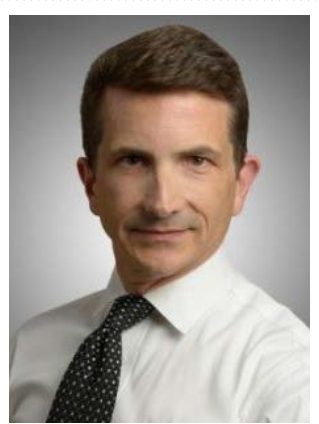

Drew Lanier, University of Central Florida

Teaching Incentive Program Award

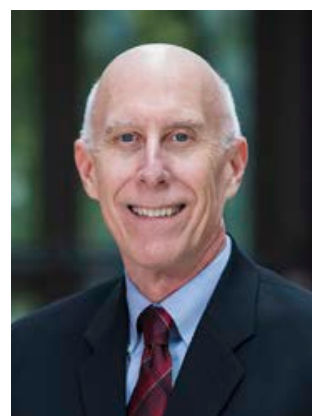

H.W. Perry, University of Texas at Austin Friar Centennial Teaching Fellowship

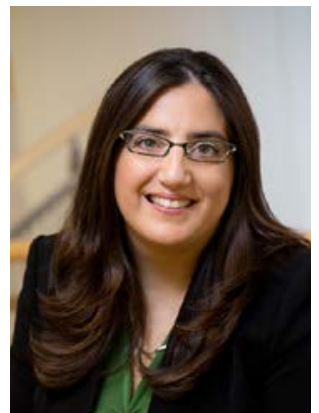

Gisela Sin, University of Illinois Dean's Award for Excellence in Undergraduate Education
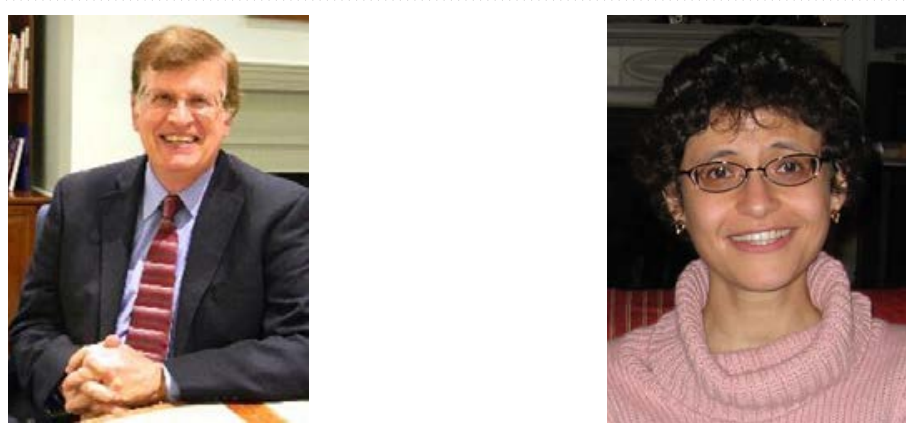

E. Fletcher McClellan, Elizabethtown College

Engaging Educator Award 2018

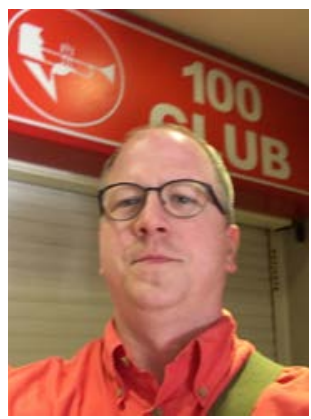

David Peterson, Iowa State University College of Liberal Arts and Sciences Award for Outstanding Achievement in Teaching

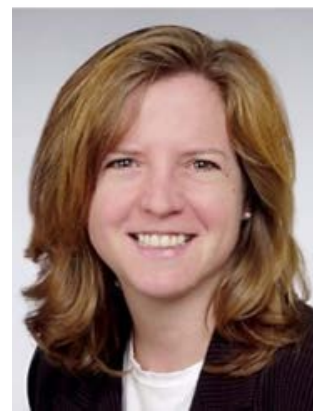

Kimberly Cowell-Meyers, American University

American University School of Public Affairs Award for Outstanding Teaching in a Full-Time Appointment
Noha Shawki, Illinois State University Office of International Studies and Programs Faculty/Staff Internationalization Award

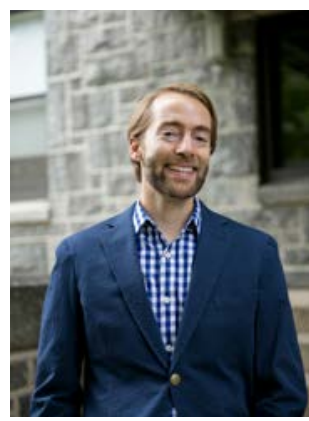

Joel Schlosser, Bryn Mawr College Rosalyn R. Schwartz Teaching Award 